\title{
STEM CELL RESEARCH-CONCEPT AND CONTROVERSIES
}

\author{
O.O. Kalu \\ Department of Obstetric and Gynaecology, University of Benin Teaching Hospital
}

The concept of stem cell research is unarguably one of the most profound concepts of our time and the controversies surrounding it are both complex and difficult to analyse. The issue is hotly debated by all and sundry, among scientists and researchers, in government circles, among people of different faith, even within the Church as many of the same faith are coming to different conclusions. Many are discovering that the more they know about the subject, the less certain they are about the right ethical and moral conclusions to be made.

This article aims to define and explain what stem cells are, the types of stem cells, the extent of stem cell research, the relationship between stem cell research and human cloning, the arguments of those in support of it and that of those in opposition to it. It finally examines the present state of stem cell research and its possible future direction.

\section{STEM CELLS}

Stem cells are undifferentiated cells that retain the ability to produce an identical copy of themselves when they divide (clone) and differentiate into other cell types. In humans a stem cell can be coaxed into developing into the 220 cell types found in the human body (e.g. blood cells, heart cells, brain cells, etc.). Some researchers regard them as offering the greatest potential for the alleviation of human suffering since the advent of antibiotics.
Stem cells are typed based on the source from which they are derived and also based on their potency. According to potency, totipotent stem cells are produced from the fusion of an egg and sperm cell. Cells produced by the first few divisions of the fertilized eggs are also totipotent and can differentiate into embryonic and extra-embryonic cell types. Pluripotent stem cells are the descendants of totipotent cells and can differentiate into cells derived from the three germ layers namely, epidermal, mesodermal and endodermal cells. Multipotent stem cells can produce cells from only one germ layer and give rise to only cell types of a closely related family - for example, haemopoietic stem cells that can differentiate into red blood cell, white blood cells, platelets etc. Unipotent stem cells are those that produce only one cell type but their property of selfrenewal distinguishes them from nonstem cells.

According to source, stem cells can be categorised into either adult, embryonic, cancer or cord blood stem cells. Adult stem cells are undifferentiated cells found among differentiated cells of a specific tissue. They are mostly multipotent cells and are more accurately referred to as somatic stem cells because they are derived not only from adults but also from children and from the umbilical cord. Of particular interest are adult stem cells termed 'spore-like cells' that are present in all tissues and seem to 
survive long time periods and conditions. Embryonal stem cells are pluripotent cells derived from the undifferentiated inner cell mass of an early stage human embryo between 50 to 150 cells, the blastocyst.

Research into embryonal stem cells is much recent; those in humans were first isolated in 1998. Embryonal stem cells are thought to have much greater developmental potential than adult stem cells and research into embryonic stem cells remain at the zenith of stem cell research because, unlike somatic cells, embryonic stem cells are Pluripotent. However, research into human embryonic cells has attracted the greatest criticisms because destruction of the human embryo is usually required. In an attempt to reduce this, experimentations by researchers into alternative techniques involving obtaining of embryonic cells by extraction, which does not involve cloning or destruction of the embryo, is being carried out. Cancer stem cells arising through malignant transformation of adult stem cells have been proposed as source of some or all tumours as well as the cause of metastasis and relapse. The stem cell origin of leukaemia is well established while that of other tumours is under intensive investigation. Cord blood stem cells (also haemopoietic stem cells) are derived from the blood in the placenta and umbilical cord after birth. Since 1988, cord blood stem cells have been used to treat conditions like Gunthers, disease, Hunters syndrome, Hurlers syndrome, Acute lymphoblastic leukaemia and many other blood and immune disorders occurring mostly in children. The stem cells from the umbilical cord are collected by isolating the umbilical cord, cleansing it and withdrawing blood from the umbilical vein and tissue typing the blood before storage in liquid nitrogen for later use. Subsequent use may be allogenic use (when used on another person), autologous use (when used on the same person) or syngeneic use (when used on identical individuals e.g. homozygous twins). Stem cell research using umbilical cord cells share the same advantage of wider acceptance as research into adult stem cell but has the additional advantage of not being likely to be rejected in that the cells have not yet developed the features that can be recognised and attacked by the recipients immune system when used allogenically. Also because umbilical cord lacks well-developed immune cells, there is less chance that a transplanted cell would attack the recipients body (Graft vs Host reaction).

\section{STEM CELL RESEARCH AND CLONING}

Stem cell research is not synonymous with cloning. In human cloning, DNA from the nucleus of a person is inserted into an egg whose genetic material has been removed, and the egg is then stimulated to begin embryonic development. The resulting cloned embryo will be almost genetically identical to the person supplying the body cells. However, human cloning issues may overlap with stem cell issues in that a cloned embryo maybe destroyed to provide genetically matched clones of a person so the cells will not be rejected as foreign tissues when used for transplant purposes. There is also the linking of some stem cell research with cloning with the possibilities of some cloning research involving the 
creation of embryos with devastating illnesses from the body cells of sick patients with the aim of studying the early progress of such disease.

Though both human cloning research and human stem cell research have experienced strong opposition by the Church and Pro-life organizations, the opposition to cloning has been almost total, involving even Pro-abortion organisations, as cloning is largely viewed as a means of asexually reproducing humans, apart from the ethical issue of life destruction that is the foundation of human cloning.

\section{STEM CELL RESEARCH - PROS}

Those in favour of continued research into stem cell cite the numerous advantages of such research. Clearly, stem cell research has helped in advancing knowledge about how organisms develop from a single cell and how healthy cells replaced damaged cells in organisms.

The most important practical application of research into stem cells is that it has encouraged leading scientists to explore the possibility of cell-based therapies to treat diseases, a branch of medicine referred to as Regenerative or Reparative medicine. This is already being applied using adult stem cells where adult stem cell lines have been widely applied in the treatment of leukaemia (Bone Marrow transplant). Adult stem cell lines are also presently being experimented within the treatment of Parkinson's disease, spinal cord injury, sickle cell anaemia, heart damage, corneal damage, etc. To be useful for transplant purposes, stem cells must be reproducibly made;

Produce extensively and generate sufficient tissues; differentiate into desired cell type(s); survive in recipient after transplantation; Integrate in surrounding tissues after transplantation; function appropriately for duration of recipient life; avoid harming the recipient in any way.

Research into stem cells have helped provide information about the evolution of diseases and cancers. Research is ongoing towards the identification of the cellular signals that turn specific genes on and off to influence the differentiation of stem cells into different specialized cells and transformation of cells into cancer cells.

A further area of use of Stem Cell Research is in the testing of new drugs. For example, by determining the safety of a new drug on differentiating cells generated from human Pluripotent cell lines, its effect on human tissues can be predicted.

\section{STEM CELL RESEARCH}

Opposition to Human Stem Cell Research has been provided not only by the church but by many pro-life and ethical organisations including the Coalition of Americans for Research Ethics and the Catholic Church. However it must be emphasized that this opposition is almost completely towards embryonic Stem Cell Research. The major argument to the embryonic Stem Cell Research involves the direct destruction of human life. They contend the argument that most of the stored embryos, particularly those denoted from IVF programmes, would eventually die, is untenable as the fact that every adult human being would die is not an excuse to commit murder, manslaughter or suicide. They insist that there should be respect for both the suffering patient that would require stem cell therapy and the stored embryo, and would rather support researchers into adult 
stem cells or any other that would not involve the destruction of an already fertilized egg. They emphasized that embryonic stem cells are yet to be used to treat any human patient and that animal trials suggests that they are to genetically unstable and too likely to form lethal tumours to be used for treatment anytime soon.

\section{STEM CELL RESEARCH — PRESENT STATE}

The study of stem cells is attributed as beginning in the 1960s after research by Canadian Scientists Ernest A. McCulloch and James E. Till. This was after evidence of adult neuro genesis and ongoing stem cell activity in the brain was demonstrated contradicting caja's "no new neurons" dogma. However, research into embryonic Stem Cells gained prominence from 1998 when James Thompson and co-workers derived the first human embryonic stem cell line at the University of WisconsinMadison. Since then, research into stem cells by government, private and profit making organisations has resulted in the development of more than 60 genetically diverse embryonic cell lines.

(A stem cell line is an ongoing living colony of stem cells in a laboratory from which cells can be obtained for research and other purpose).

These existing stem cell lines were obtained from embryos that have already been destroyed Some researchers believe that as at the middle of 2006 only 22 cell lines are remaining and most are of limited usefulness because of DNA damage. Unlikely embryonic cells, adult cell research has resulted in fewer germ cell lines. Stem cell extraction from adult tissues, though done without any harm to the subject, are difficult to remove and are severely limited in quantity.

\section{STEM CELL RESEARCH - THE FUTURE}

The major influence on the future of research into stem cells will be the level of funding it receives. Presently, funding for stem cell research is provided mainly by the government, with most governments favouring researches involving adult and umbilical cord stem cells. In fact, a major refocusing in the direction into stem cell research was made in July 19, 2006 when the president of the USA, President George W. Bush, vetoed a Congressional decision (made following the death of former US President Ronald Reagan due to Alzheimer's disease in June 2004) removing restrictions on embryonic stem cell research. The USA are the major sponsors of Stem Cell Researches and have donated \$35 million towards Stem Cell Research in 2006.

\section{REFERENCES}

1. Stem Cell Information: The official NH source for Stem Cell Research

2. Turksen K, Troy T.C. Human Embryonic Stem Cells: Isolation, Maintenance and Differentiation, Methods Mol Biol. 2006; 331: 1 - 12.

3. Polak J.M., Bishop A.E. Stem Cell and Tissue Engineering: Past, Present and Future, Ann N.Y. Academy Science 2006; 1068; 1068; 352 - 66. 